\title{
Desquamative Interstitial Pneumonia: an Idiopathic Interstitial Pneumonia with a Possibility of Spontaneous Regression
}

Interstitial pneumonia of unknown etiology or idiopathic interstitial pneumonia (IIP) is basically a clinical term (1). IIP usually begins with exertional dyspnea and bilateral pulmonary infiltrates on chest X-rays. The etiology of IIP can not be determined even after careful investigation of the patients' past medical history, and environmental and occupational history. Any disease that is possibly complicated by a systemic disease is excluded as a possible etiology. Clinical courses are grouped into either acute, subacute, or chronic type. In the chronic cases, an aggravated acute problem sometimes occurs and there is usually a poor prognosis. Corticosteroids are not effective treatment in most cases, although these drugs have been effective in a small number of cases. Pathologically, the following pulmonary diseases have been encountered among patients with IIP and the pathologic classification of IIP offers a more precise basis for assessing prognosis, and choosing therapy for patients with IIP: diffuse alveolar damage/acute interstitial pneumonia (DAD/AIP), usual interstitial pneumonia (UIP), desquamative interstitial pneumonia (DIP), lymphocytic interstitial pneumonia (LIP), bronchiolitis obliterans organizing pneumonia (BOOP), and unclassified/nonclassifiable interstitial pneumonia (NCIP) (1). Among these, DIP was originally reported as a chronic interstitial pneumonia from a study of open lung biopsy cases in 1965 (2).

See also p 728.

The histology of DIP shows a relative uniformity of the lesion throughout the tissue sample, sparse interstitial cellular infiltrates including an appreciable number of plasma cells and eosinophils, prominent lining of alveoli by large, rounded cells, and abundant mononuclear cells filling many small air spaces (3). The numerous large mononuclear cells in the airspaces were thought to be "desquamated" hyperplastic alveolar lining cells. Hence, the term "DIP" was coined (2). However, these cells were proved to be largely macrophages by electron microscopy studies (4-7), studies of phagocytic activity (8), and immunohistology as reported in this issue of Internal Medicine (9).

Reports of DIP are rather few $(2,3,10-12)$. DIP is less than $10 \%$ of UIP (1). The onset is usually in the middle-aged with a male predominance and $90 \%$ of DIP cases are cigarette smokers $(3,11)$ although there are some pediatric cases $(10)$. While several cases of DIP had a history of collagen vascular disease
(12), dust exposure $(5-7,12)$, or drug treatment (7), the majority of DIP cases are idiopathic $(3,12)$.

The major differential diagnosis of DIP is respiratory bronchiolitis-associated interstitial lung disease (RB-ILD) in addition to UIP and eosinophilic granuloma of lung $(1,6,7,11)$. After histologic review of 58 consecutive cases of interstitial lung disease with open-lung biopsy specimens coded as DIP or possible DIP, nine cases were assessed as RB-ILD and 36 cases were interpreted as classic DIP (11). All cases of RB-ILD are cigarette smokers. Histologically, the pulmonary lesions of RB-ILD are predominantly in and around the respiratory bronchioles.

DIP has been reported to have a high frequency of steroid responsiveness compared to UIP (3). Before the description of BOOP in 1985 and nonspecific interstitial pneumonia/fibrosis (NSIP) or NCIP in 1994, DIP had been considered to be the single type of reversible idiopathic interstitial pneumonia. In the study of Carrington and his colleagues, long-term improvements by steroid therapy were observed in $68 \%$ of 26 DIP cases while only $8 \%$ of 26 UIP cases who received adequate therapy showed such improvements (6). Similar results of steroid therapy for DIP were reported by other investigators $(10,11)$. In the study of Carrington et al., 21.9\% of 32 untreated DIP cases improved spontaneously and six cases recovered fully (3). Regarding the mortality, 14 of 40 DIP cases died with a mean time to death of 16.8 years, while 48 of 53 UIP cases died with a mean time to death of 6.2 years (6). Although it has been discussed that DIP may represent the early stage and UIP the late stage of idiopathic pulmonary fibrosis (IPF) $(3,6,7,12)$, spontaneous regression in DIP strongly suggests that DIP is a different disease from UIP $(6,7)$. The case report of DIP in this issue of Internal Medicine (9) illustrates to physicians the more favorable prognosis of the disease compared to UIP in the clinical setting of IIP.

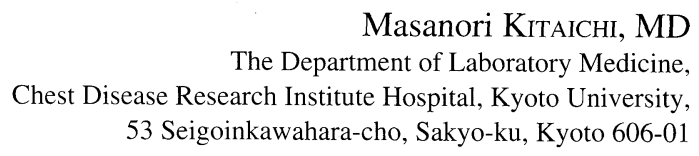

\section{References}

1) Kitaichi M. Pathologic features and the classification of interstitial pneumonia of unknown etiology. Bull Chest Dis Res Inst, Kyoto Univ 23: $1,1990$. 
2) Liebow AA, Steer A, Billıngsley JG Desquamative interstitial pneumonia. Am J Med 39: 369, 1965

3) Carrington CB, Gaensler EA, Coutu RE, FitzGerald MX, Gupta RG Natural history and treated course of usual and desquamatıve interstitial pneumonia N Engl J Med 298: 801, 1978

4) Farr GH, Harley RA, Hennigar GR Desquamative interstitıal pneumonia: an electron microscopic study Am J Pathol 60: 347, 1970

5) Corrin $B$, Price $A B$ Electron microscopic studies in desquamative interstitial pneumonia associated with asbestos Thorax 27: 324, 1972

6) Colby TV, Carrıngton CB Interstitial lung disease In, Thurlbeck WM, Churg AM (eds) Pathology of the Lung, Thieme Medical Publishers, New York, 2nd Ed., 1995, p 589

7) Katzenstein A-LA, Myers JL. Surgical Pathology of Non-Neoplastıc Lung Disease, WB Saunders Co , Philadelphia, 3rd Ed , 1997, p. 48 and p 81

8) Fromm GB, Dunn LJ, Harrıs JO. Desquamative interstitial pneumonitis Characterization of free intraalveolar cells Chest 77: 552, 1980.

9) Matsuo K, Tada S, Kataoka M, et al Spontaneous remission of desquamatıve interstitial pneumonia. Intern Med 36: 728, 1997

10) Feigin DS, Friedman PJ Chest radıgraphy in desquamatıve interstitial pneumonitis' a review of 37 patients AJR Am J Roentgenol 134: 91, 1980

11) Yousem SA, Colby TV, Gaensler E Respiratory bronchiolitıs-associated interstitial lung disease and its relationship to desquamatıve interstitial pneumonia Mayo Clın Proc 64: 1373, 1989

12) Hartman TE. Prumack SL, Swensen SJ, Hansell D, McGunness G, Mueller NL Desquamative interstitial pneumonia thin-section CT findings in 22 patıents Radıology 187: 787, 1993 